\title{
Calcium manganite as oxygen electrode materials for reversible solid oxide fuel cell
}

\author{
Chengsheng $\mathrm{Ni}^{*}$ and John T. S. Irvine \\ Received 18th February 2015, Accepted 7th April 2015 \\ DOI: $10.1039 / \mathrm{c} 5 \mathrm{fd} 00026 \mathrm{~b}$
}

\begin{abstract}
For an efficient high-temperature reversible solid oxide fuel cell (RSOFC), the oxygen electrode should be highly active for the conversion between oxygen anions and oxygen gas. $\mathrm{CaMnO}_{3-\delta}(\mathrm{CM})$ is a perovskite that can be readily reduced with the formation of $\mathrm{Mn}^{3+}$ giving rise to oxygen defective phases. $\mathrm{CM}$ is examined here as the oxygen electrode for a RSOFC. $\mathrm{CaMn}_{0.9} \mathrm{Nb}_{0.1} \mathrm{O}_{3-\delta}$ (CMN) with $\mathrm{Nb}$ doping shows superior electric conductivity $\left(125 \mathrm{~S} \mathrm{~cm}^{-1}\right.$ at $\left.700{ }^{\circ} \mathrm{C}\right)$ compared with $\mathrm{CM}\left(1-5 \mathrm{~S} \mathrm{~cm}^{-1}\right.$ at $700{ }^{\circ} \mathrm{C}$ ) in air which is also examined for comparison. X-ray diffraction (XRD) data show that $C M$ and $C M N$ are compatible with the widely used yttria-stabilized zirconia (YSZ) electrolyte up to $950{ }^{\circ} \mathrm{C}$. Both materials show a thermal expansion coefficient (TEC) close to $10.8-10.9 \mathrm{ppm} \mathrm{K}^{-1}$ in the temperature range between $100-750{ }^{\circ} \mathrm{C}$, compatible with that of YSZ. Polarization curves and electrochemical impedance spectra for both fuel cell and steam electrolysis modes were investigated at $700{ }^{\circ} \mathrm{C}$, showing that $\mathrm{CM}$ presented a polarization resistance of $0.059 \Omega \mathrm{cm}^{2}$ under a cathodic bias of $-0.4 \mathrm{~V}$ while CMN gave a polarization resistance of $0.081 \Omega \mathrm{cm}^{2}$ under an anodic bias of $0.4 \mathrm{~V}$. The phase stability up to $900{ }^{\circ} \mathrm{C}$ of these materials was investigated with thermogravimetric analysis (TGA) and variable temperature XRD.
\end{abstract}

\section{Introduction}

Renewable energy sources have attracted much attention in recent years to reduce the dependency on fossil fuels that cause pollutant gas emission and climate change. ${ }^{1}$ The lack of synchronization between electricity production and consumption makes energy storage crucial for the grid to function effectively. A reversible solid oxide fuel cell (RSOFC) that incorporates the production of $\mathrm{H}_{2}$ fuel from electricity via a solid oxide electrolysis cell (SOEC) and electricity generation via a solid oxide fuel cell (SOFC) could be an efficient and low-cost solution for energy conversion and storage. Operation at high temperatures $\left(500-1000{ }^{\circ} \mathrm{C}\right)$ reduces the electrical energy requirement for the electrolysis and also increases the thermal efficiency of the power-generating cycle. ${ }^{2-4}$ It is expected that through the combination of a high-temperature reactor and a high temperature electrolyser, the process will achieve an overall thermal conversion efficiency of $48-59 \%$ 
while avoiding the challenging chemistry and corrosion issues associated with the thermochemical processes. ${ }^{4}$

Yttria-stabilized zirconia (YSZ) is widely used as the solid oxide electrolyte due to its high stability at low oxygen partial pressure at elevated temperature. Sr-doped $\mathrm{LaMnO}_{3}$ (LSM) typically fulfils the requirement for use as a cathode in solid oxide fuel cells (SOFCs) operating at high temperature $\left(T>850{ }^{\circ} \mathrm{C}\right)$ due to its high thermal and chemical stability and catalytic activity for oxygen reduction in composites with YSZ, but it exhibits much higher polarization losses as a cathode than its $\mathrm{Fe}$ and $\mathrm{Co}$ analogues, Sr-doped $\mathrm{LaFeO}_{3}$ (LSF) and Sr-doped $\mathrm{LaCoO}_{3}$ $(\mathrm{LSCO})^{5-7}$ at intermediate temperatures $\left(500-800{ }^{\circ} \mathrm{C}\right)$. For an SOEC with a configuration of $\mathrm{Ni}(\mathrm{O})-\mathrm{YSZ}|\mathrm{YSZ}| \mathrm{LSM}-\mathrm{YSZ}$ at $700{ }^{\circ} \mathrm{C}$, the loss from the oxygen electrode accounts for most of the total polarization loss, ${ }^{5,6,8}$ so it would be useful to minimize the energy loss from the oxygen electrode for a better performance. Although high performance has been demonstrated, neither LSF nor LSCo are compatible with the YSZ electrolyte due to the high thermal expansion coefficient and reactivity during the high-temperature firing of the electrode on electrolyte during processing. ${ }^{9}$

Novel materials compatible with YSZ need to be explored for better performance as the oxygen electrode of RSOFCs at temperatures below $800{ }^{\circ} \mathrm{C}$ for the purpose of using metallic interconnects and also reducing degradation and maintenance costs. $\mathrm{AMnO}_{3-\delta}(\mathrm{A}=\mathrm{Ba}, \mathrm{Sr}$ or $\mathrm{Ca})$ is a perovskite without expensive rare-earth element where most $\mathrm{Mn}$ shows a valence of IV and gives rise to the formation of an oxygen vacancy when $\mathrm{Mn}^{\mathrm{IV}}$ is partially reduced to $\mathrm{Mn}^{\mathrm{III}}$. Both $\mathrm{BaMnO}_{3-\delta}$ and $\mathrm{SrMnO}_{3-\delta}$ were reported to have a hexagonal structure ${ }^{10}$ and show very low electric conductivity, ${ }^{11}$ but $\mathrm{CaMnO}_{3-\delta}(\mathrm{CM})$ has an orthorhombic $\mathrm{GdFeO}_{3}$ structure and shows a conductivity of higher than $1 \mathrm{~S} \mathrm{~cm}^{-1}$ at $700{ }^{\circ} \mathrm{C}^{12}$ The addition of oxyanion dopants (such as $\mathrm{Si}, \mathrm{B}$ and $\mathrm{P}$ ) in to a $\mathrm{Ca}_{1-y} \mathrm{Sr}_{y} \mathrm{MnO}_{3-\delta}$ system was reported to increase the conductivity by increasing the ratio of $\mathrm{Mn}^{\mathrm{III}}$ and inhibit the formation of hexagonal $\mathrm{SrMnO}_{3-\delta} \cdot{ }^{\mathbf{1 1 , 1 3 , 1 4}}$ However, these nonmetallicoxide-doped perovskites showed a reactivity even with CGO at $1000{ }^{\circ} \mathrm{C},{ }^{14} \mathrm{a}$ common buffer layer to prevent the reaction between YSZ and the oxygen electrode materials. Oxygen-deficient $\mathrm{CaMn}_{1-x} \mathrm{Nb}_{x} \mathrm{O}_{3-\delta}(x<0.6)$ has been used as catalyst thermoelectric materials and sensors ${ }^{12,15}$ thanks to the change in valence of $\mathrm{Mn}$, crystal structure and oxygen content. Since $\mathrm{CaMn}_{0.9} \mathrm{Nb}_{0.1} \mathrm{O}_{3-\delta}(\mathrm{CMN})$ showed the optimum $\mathrm{Nb}$ doping content in respect to the high electric conductivity $\left(125 \mathrm{~S} \mathrm{~cm}^{-1}\right.$ at $\left.700{ }^{\circ} \mathrm{C}\right),{ }^{12,16}$ it is also studied as a novel oxygen electrode for more practical benefits in the current collection. CM and CMN are for the first time electrochemically characterized as oxygen electrodes for an RSOFC: they both show high catalytic activity for the reduction and oxidation of oxygen at 700 ${ }^{\circ} \mathrm{C}$. A clear relation between the physical/chemical property variation, e.g. TEC, microstructure and oxygen content thanks to the addition of $\mathrm{Nb}$ on the $\mathrm{B}$ site of a perovskite, and the difference in electrochemical performance of the oxygen electrode from both materials under an anodic and cathodic bias were established in this study.

\section{Experimental}

Stoichiometric amounts of $\mathrm{CaCO}_{3}$ (99\%, Alfa Aesar), $\mathrm{MnO}_{2}$ (98\%, Alfa Aesar, metal basis) and $\mathrm{Nb}_{2} \mathrm{O}_{5}(99.9985 \%$, Alfa Aesar, metal basis) were mixed in an agate 
tray with a pestle and pre-calcined in a alumina crucible at $1000{ }^{\circ} \mathrm{C}$ for 12 hours. Then the 20 gram admixture was ground in a planetary ball-mill at $300 \mathrm{rpm}$ for 30 min for better mixing and then pelletized and fired at $1300{ }^{\circ} \mathrm{C}$ for 20 hours for the correct perovskite phase. The heating and cooling ramp rates were $10{ }^{\circ} \mathrm{C} \mathrm{min}^{-1}$ for both the calcination and final firing state. The pellets were then crushed and ground using an agate mortar for characterization with thermogravimetric analysis (TGA) and room temperature X-ray diffraction (XRD). Dense pellets of dilatometry measurement were obtained by calcining the ball-milled powder at $1300{ }^{\circ} \mathrm{C}$ for 20 hours and then cooling to room temperature at $1{ }^{\circ} \mathrm{C} \mathrm{min}^{-1}$ to avoid any cracking during the cooling process. The dimensions for the pellet were approximately $10 \mathrm{~mm}$ in diameter and $2 \mathrm{~mm}$ in thickness. The thermal expansion of the dense pellets was analyzed with a high-temperature dilatometer (Netzsch, DIL 402C) in a flowing air atmosphere. The samples were heated and cooled to $900{ }^{\circ} \mathrm{C}$ at a rate of $3{ }^{\circ} \mathrm{C} \min ^{-1}$ and dwelled at $900{ }^{\circ} \mathrm{C}$ for 1 hour. For the compatibility test between the materials and YSZ, the $1.0 \mathrm{~g}$ powder of $\mathrm{CM}(\mathrm{N})$ and $1.0 \mathrm{~g}$ YSZ was agate-mixed, pressed under $150 \mathrm{MPa}$ and then calcined at $950{ }^{\circ} \mathrm{C}$ for 5 hours at a ramp rate of $10{ }^{\circ} \mathrm{C} \mathrm{min}^{-1}$. XRD was performed at room temperature on a PANalytical Empyrean diffractometer operated in reflection mode using $\mathrm{Cu}$ $K_{\alpha 1}$ (wavelength: $1.5406 \AA$ ) radiation for the analysis of unit cell and structure. The XRD data were simulated with GSAS simulation software, in order to determine the unit cell and arrangement of atoms in the materials. TGA was performed on a NETZSCH 49C thermo-gravimeter up to $900{ }^{\circ} \mathrm{C}$ at a ramp rate of $10{ }^{\circ} \mathrm{C} \mathrm{min}^{-1}$.

Pellets of $8 \% \mathrm{Y}_{2} \mathrm{O}_{3}$-stabilized zirconia (8YSZ) powder were pressed uni-axially at a pressure of $80 \mathrm{MPa}$ and calcined at $1500{ }^{\circ} \mathrm{C}$ for 10 hours to give a $>95 \%$ dense electrolyte. The electrolyte diameter was controlled to be $20 \mathrm{~mm}$. In order to improve the adhesion between the electrode and electrolyte, the hand-ground powder was milled with zirconia balls ( $\sim 1 \mathrm{~mm}$ in diameter) again at $650 \mathrm{rpm}$ in isopropanol for 30 minutes in a planetary ball-mill to get the fine source powders for the fabrication of the electrode. High temperature XRD measurements were performed on a Panalytical diffractometer operated in reflection mode using a Mo target (wavelength of $K_{\alpha 1}=0.7093 \AA$ and $K_{\alpha 2}=0.71359 \AA$ ). The samples were stabilized at each temperature for 15 minutes before each scanning in the $2 \theta$ range from 10 to $50^{\circ}$. Three grams of the mixed powder was mixed with a vehicle containing polyvinyl butyral (PVB) and fish oil to make the slurry that would be applied onto a dense 8YSZ electrolyte through screen printing. Three screenprinted layers with intermediate dryings at $80^{\circ} \mathrm{C}$ were utilized to give an electrode of around $20 \mu \mathrm{m}$ thickness after firing. A good bonding between the electrode and electrolyte was obtained after calcination at $950{ }^{\circ} \mathrm{C}$ for 2 hours at a ramp rate of $3{ }^{\circ} \mathrm{C} \min ^{-1}$.

Two configurations of cells were used to test the performance of the air electrode in this paper. A symmetrical cell contains two identical oxygen electrodes on both sides of the 8YSZ electrolyte of $1.8 \mathrm{~mm}$ in thickness and $2 \mathrm{~cm}$ in diameter. The symmetrical cells were employed to measure the polarization resistance of the electrode in static air in the temperature range between $550{ }^{\circ} \mathrm{C}$ and $700{ }^{\circ} \mathrm{C}$. The other configuration, called a three-electrode system, was composed of an oxygen electrode, a $\mathrm{Ni}(\mathrm{O})-Y S Z$ fuel electrode and a reference electrode on the edge of the electrolyte $(\sim 1.0 \mathrm{~mm}$ thick). The Ni(O)-YSZ fuel electrode $(13 \mathrm{~mm}$ in diameter) was prepared by screen printing of the slurry containing $55 \mathrm{wt} \% \mathrm{NiO}$ and $45 \mathrm{wt} \%$ YSZ onto the electrolyte plus a firing at $1350{ }^{\circ} \mathrm{C}$ for 3 hours. A 
$\left(\mathrm{La}_{0.8} \mathrm{Sr}_{0.2}\right)_{0.95} \mathrm{MnO}_{3}$ slurry was painted onto the edge of the electrolyte and dried at $80{ }^{\circ} \mathrm{C}$ for 30 minutes and then fired at $950{ }^{\circ} \mathrm{C}$ for two hours along with the firing of the oxygen electrode. A silver wire $(0.5 \mathrm{~mm}$ thick $)$ was bundled the LSM coating and then fired at $700{ }^{\circ} \mathrm{C}$ again to provide the reference. The humidified gas $\left(\mathrm{N}_{2}-50 \% \mathrm{H}_{2} \mathrm{O}-3 \% \mathrm{H}_{2}\right)$ in the fuel electrode was produced by injecting deionised water into an evaporator to mix with the nitrogen carrier gas containing $5 \% \mathrm{H}_{2}$, as described previously. ${ }^{2}$

Silver paste was used for the current collection for both the symmetrical-cell and three-electrode testing. The impedance was measured with a Solartron electrochemical workstation equipped with a lock-in frequency analyzer (Solartron 1260) with a sine wave of $10 \mathrm{mV}$. The three-electrode testing procedure commenced with sealing of the fuel electrode side of cells to the alumina tube of the testing jig, which was then placed in a vertical furnace. Scanning electron microscopy (SEM) and transmission electron microscopy (TEM) of the powders and tested samples are taken on a Jeol 6700F microscope and Jeol 2011, respectively.

\section{Result and discussion}

\section{Crystal structure and compatibility with YSZ}

The crystal structure of $\mathrm{CM}$ and CMN was regarded as an orthorhombic structure, ${ }^{\mathbf{1 2 , 1 5 , 1 7}}$ with the cell parameters of $\sqrt{ } 2 a_{\text {cubic }} \times 2 a_{\text {cubic }} \times \sqrt{ } 2 a_{\text {cubic }}\left(a_{\text {cubic }}\right.$ refers to the cubic structure), involving successive cooperative rotations of $\mathrm{MnO}_{6}$ octahedra around the $\langle 111\rangle$ crystallographic axis. The cell parameters of calcium manganite depend on the oxygen content that can be affected by the synthesis route in terms of firing temperature and cooling rate. ${ }^{18,19}$ The cell parameters determined from powder XRD are shown in Table 1, showing that the addition of $\mathrm{Nb}$ on the Mn site enlarges the cell parameters.

The reaction between zirconia and the cathode perovskite materials, especially those containing cobalt on the B-site, would cause the formation of insulating products, such as $\mathrm{La}_{2} \mathrm{Zr}_{2} \mathrm{O}_{7}$ or $\mathrm{SrZrO}_{3}$ that would block the transport of electrons/ ions between the electrode and electrolyte. The XRD patterns (Fig. 1) show no observable reaction after 5 hour annealing in air in contact with YSZ at $950{ }^{\circ} \mathrm{C}$. No obvious variation of lattice parameter (Table 1) was observed. Thermodynamic calculation has predicted the formation of $\mathrm{CaMn}_{2} \mathrm{O}_{4}$ for the $\mathrm{CM}-\mathrm{YSZ}$ system at

Table 1 Cell parameters (in $\AA$ ) and volume $\left(\AA^{3}\right)$ of CM and CMN with symmetry of Pnma, oxygen nonstoichiometry, $(\delta)$ from TGA measurement and the Goldschmidt tolerance factors, $\tau^{a}$

\begin{tabular}{|c|c|c|c|c|c|c|c|}
\hline & $a$ & $b$ & $c$ & $V$ & $\delta$ & $\frac{\mathrm{Mn}^{\mathrm{IV}}}{\mathrm{Mn}^{\mathrm{IV}}+\mathrm{Mn}^{\mathrm{III}}}$ & $\tau$ \\
\hline CM & $5.2808(3)$ & 7.45525(1) & $5.2668(2)$ & $207.258(4)$ & 0.028 & 0.944 & 0.878 \\
\hline CMN & $5.3316(2)$ & 7.5119(2) & $5.3074(2)$ & $212.504(4)$ & 0.017 & 0.851 & 0.871 \\
\hline $\mathrm{CM}^{a}$ & $5.2825(1)$ & $7.4563(2)$ & $5.2706(4)$ & $207.603(4)$ & - & - & - \\
\hline $\mathrm{CMN}^{a}$ & $5.3326(2)$ & $7.5112(2)$ & $5.3058(3)$ & 212.532(9) & - & - & - \\
\hline
\end{tabular}




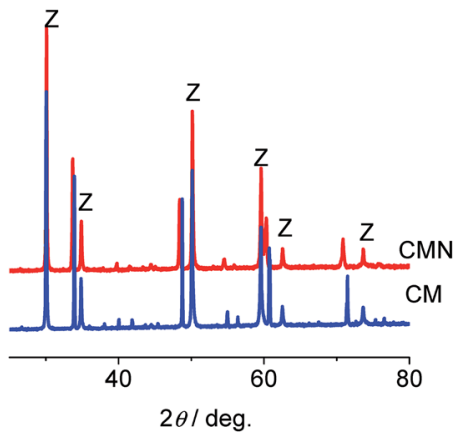

Fig. 1 XRD patterns of $C M$ and $C M N$ with YSZ after calcination at $950{ }^{\circ} \mathrm{C}$ for 5 hours. The peaks indexed with "Z" belong to YSZ and the rest to perovskites.

$1400{ }^{\circ} \mathrm{C},{ }^{20}$ which was not observed in our case due to the relatively low temperature. The compatibility of LSM is limited to $1200{ }^{\circ} \mathrm{C}$ and can be improved by A-site deficiency. Attempts have been made to prepare A-site deficient $\mathrm{Ca}_{0.95} \mathrm{MnO}_{3-\delta}$ and $\mathrm{Ca}_{0.95} \mathrm{Mn}_{0.9} \mathrm{Nb}_{0.1} \mathrm{O}_{3-\delta}$ using the same method as for their stoichiometric counterparts, but $\mathrm{CaMn}_{2} \mathrm{O}_{4}$ persisted as the impurity in both materials, even though the phase diagram ${ }^{21}$ of $\mathrm{CaO}-\mathrm{Mn}_{2} \mathrm{O}_{3}$ indicated that $10 \% \mathrm{~A}-$ site deficient was achievable. The A-site deficiency of a perovskite was reported to be controlled by the bond energy of $\langle\mathrm{B}-\mathrm{O}\rangle^{22}$ and 5\% A-site deficiency for LSM was reported.

\section{Chemical and structural transformations with temperature variation}

The oxygen non-stoichiometries, $\delta$, were obtained by $\mathrm{H}_{2}$-reduction TGA. In order to analyze the TGA data, the initial assumption was made that the final products of the reduction contained $\mathrm{Mn}$ in the +2 state and $\mathrm{Nb}$ in the +5 state..$^{15}$ The oxygen non-stoichiometry, $\delta$, is listed in Table 1 , and the ratio of $\mathrm{Mn}^{\mathrm{IV}}$ to $\mathrm{Mn}^{\mathrm{IV}}+\mathrm{Mn}^{\mathrm{III}}$ is also calculated, assuming the charge neutrality of the perovskite. It can be seen that the oxygen content in $\mathrm{CMN}$ is higher than that of CM. A higher oxygen content in niobium doped CM was also reported by Kruth et al. ${ }^{15}$ for the samples synthesized in air, due to the higher thermal stability with $\mathrm{Nb}$ doping during the high temperature synthesis. TGA under air and oxygen (Fig. 2) can provide information on structural and chemical changes occurring in the volume of CM and $\mathrm{CMN}$ with temperature variation. It can be seen that in oxygen atmosphere, $\mathrm{CM}$ also picks more weight than $\mathrm{CMN}$ to make the $\delta$ value near zero after calcination at $900{ }^{\circ} \mathrm{C}$ for 1 hour. $\mathrm{CMN}$ is more stable against thermal treatment in air up to $900{ }^{\circ} \mathrm{C}$. The $\delta$ values of $\mathrm{CM}$ and CMN change to 0.099 and 0.025 at $900{ }^{\circ} \mathrm{C}$ in air, respectively. The changes of oxygen content caused by the valence variation of the transition metal were anticipated to be beneficial to the electrochemical performance of the oxygen electrode. ${ }^{23}$

The Goldschmidt tolerant factor for perovskite structure, $\tau$, of the materials was calculated according to the equation: ${ }^{24}$

$$
\tau=\frac{R_{\mathrm{A}}+R_{\mathrm{O}}}{\sqrt{2}\left(R_{B}+R_{\mathrm{O}}\right)}
$$




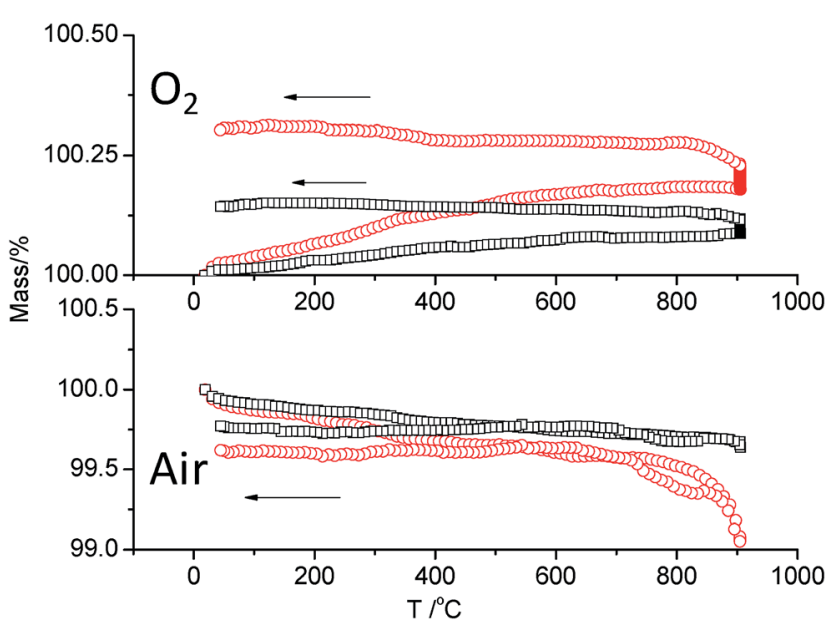

Fig. 2 TGA curves CM (open circles) and CMN (open squares) in air and $\mathrm{O}_{2}$. The heating or cooling direction is indicated with the arrow. The ramp rate is $10{ }^{\circ} \mathrm{C} \mathrm{min}^{-1}$.

where, $R_{\mathrm{A}}=$ ionic radius of larger cation, $R_{\mathrm{B}}=$ ionic radius of smaller cation, $R_{\mathrm{O}}=$ ionic radius of oxygen $(=1.40 \AA)$.

The $R_{\mathrm{B}}$ for CM and CMN was calculated via the composition weighted average ionic radii of $\mathrm{Mn}^{\mathrm{IV}}, \mathrm{Mn}^{\mathrm{III}}$ and $\mathrm{Nb}^{\mathrm{V}}$. It can be seen that the addition of $\mathrm{Nb}$ into the lattice of $\mathrm{CM}$ increases the percentage of $\mathrm{Mn}^{\mathrm{III}}$ (Table 1) and decreases the tolerance factor thanks to the larger radii of $\mathrm{Mn}^{\mathrm{III}}$ (72 $\mathrm{pm}$ for low-spin) and $\mathrm{Nb}^{\mathrm{V}}$ (78 pm) than $\mathrm{Mn}^{\mathrm{IV}}$ (67 pm for low spin) under the similar oxygen content. ${ }^{15}$ The tolerance factors of both materials are $c a$. 0.87 , less than 1 for a cubic perovskite. On the one hand, Dabrowski et $a .^{25}$ found that the thermal stability of $\mathrm{Sr}_{1-x-y} \mathrm{Ca}_{x} \mathrm{Ba}_{y} \mathrm{MnO}_{3}$ perovskites was governed by the magnitude of tolerance factor $(\tau<1)$ which can be adjusted by the oxygen content. Similarly, the stabilizing energy of a perovskite structure was found to be in a linear relationship to the tolerance factor (when $\tau<1) .{ }^{26}$ On the other hand, the substitution of a more electronegative $\mathrm{Nb}$ (electronegativity, $\left.\chi_{\mathrm{Nb}}=1.60\right)$ for $\mathrm{Mn}\left(\chi_{\mathrm{Mn}}=1.55\right)$ reduces the tendency to form oxygen vacancies. ${ }^{27}$ For example, $\mathrm{Nb}$ and Mo are reported to efficiently stabilize the cubic perovskite crystal structure of $\mathrm{SrCoO}_{3-\delta}$ oxide, which is noted for both high oxide ionic and electronic conductivity at elevated temperature. ${ }^{28,29}$ A balance of the above two factors should strike a balance to control the thermal stability of CM and CMN.

The values of TEC in flowing air are presented in Fig. 3. One can distinguish two segments with different TECs for both CM and CMN. The thermal expansion of CMN is more linear than CM in the whole temperature range. Both materials show quite similar TECs in the temperature range $25-750{ }^{\circ} \mathrm{C}$, but $\mathrm{CM}$ shows a much higher TEC between $750-900{ }^{\circ} \mathrm{C}$. A hysteresis of the shrinkage in the heating and cooling period was observed, and can be explained by the non-equilibrated release and recovery of oxygen of the bulk materials in air. Two TECs delimited at temperature $c a .750{ }^{\circ} \mathrm{C}$ were assumed for better fitting of the expansion data. At temperatures below $750{ }^{\circ} \mathrm{C}$, both materials show similar TECs, $c a .13 \mathrm{ppm} \mathrm{K}^{-1}$ for heating and $c a .11 \mathrm{ppm} \mathrm{K}^{-1}$ for cooling. On the contrary, CM shows much larger 


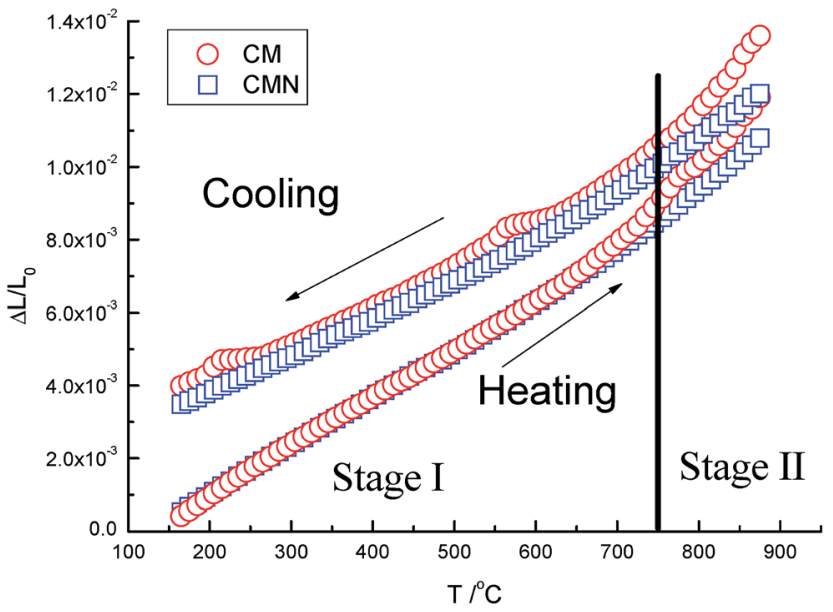

Fig. 3 Dilatometry of the CM and CMN samples in the temperature range between 150 and $900{ }^{\circ} \mathrm{C}$. The ramp rate for the heating and cooling was $3^{\circ} \mathrm{C} \mathrm{min}$ m $^{-1}$ and the samples dwelled in flowing air at $900^{\circ} \mathrm{C}$ for 1 hour before cooling down.

thermal expansion than $\mathrm{CMN}$ at temperatures above $750{ }^{\circ} \mathrm{C}$, reaching $21 \mathrm{ppm} \mathrm{K} \mathrm{K}^{-1}$ for heating and $25 \mathrm{ppm} \mathrm{K}^{-1}$ for cooling. The heavy doping of $\mathrm{Nb}$ on the B-site was reported to decrease the thermal expansion of $\mathrm{LaCoO}_{3},{ }^{30}$ but this is not obvious in our study unless at temperatures higher than $750{ }^{\circ} \mathrm{C}$. The additional expansion at higher temperatures can be a result of chemical expansion due to the change of $\mathrm{Mn}^{\mathrm{IV}}$ to the larger $\mathrm{Mn}^{\mathrm{III}}$, similar to the phenomenon observed in Sr-doped lanthanum cobalt oxide. ${ }^{31}$ It should be noted that the thermal history of the sample is also very important to the TECs of the samples, as can be seen from the discrepancy between the heating-up and cooling-down process. More importantly, the thermal expansion in the cooling stage is closer to that of YSZ and more meaningful since the stress could arise from the strain in the cooling process after the calcination of powder on the electrolyte.

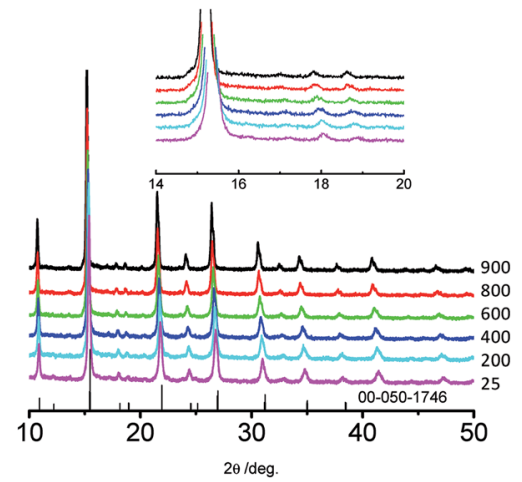

Fig. 4 High temperature XRD spectra of CMN from 25 to $900^{\circ} \mathrm{C}$ in static air. The insert is the magnified region in between $14-20^{\circ}$. The temperature $\left({ }^{\circ} \mathrm{C}\right)$ is indicated beside the graph. A standard powder diffraction file (pdf) of CM is provided to show the rough position of peaks. 
The in situ XRD patterns at temperatures up to $900{ }^{\circ} \mathrm{C}$ in air were measured to study the crystal structure of CMN presented in Fig. 4 to provide a better equilibrium than dilatometry since very fine powders (as shown afterwards in this paper) were used for the determination of lattice parameters in this study. The in situ XRD patterns of CM and CMN were performed in static air with an environmental X-ray diffractometer with Mo target. The cell parameters of CMN at room temperature calculated from XRD with Mo target are $a=5.3226$ (2) $\AA, b=$ 7.5103(2) $\AA$ and $c=5.3110(3) \AA$, and the volume of unit cell is 212.301(5) $\AA^{3}$, which are quite similar to those from the XRD using a $\mathrm{Cu} \mathrm{K}_{\alpha 1} \mathrm{X}$-ray diffractometer. The unit cell of the powder at room temperature before and after high-energy milling was checked with $\mathrm{Cu} \mathrm{K}_{\alpha 1} \mathrm{X}$-ray diffractometer, and no variation was observed. The fluorescence of Mn-ion under characteristic X-ray of $\mathrm{Cu}$ target and $\mathrm{K} \alpha_{2}$ of the Mo target would both affect the determination of cell parameters. It can be seen that CMN maintains the orthorhombic structure through the whole temperature range and the peaks shift toward the low angle direction along with increasing temperatures, indicating an expansion of the unit cells. The unit cell parameters (Fig. 5) of both materials during the heating stage were calculated by fitting the peaks into an orthorhombic structure. The linear fitting formula of unit cell parameters and parabolic fitting parameters of cell volumes are inserted in the
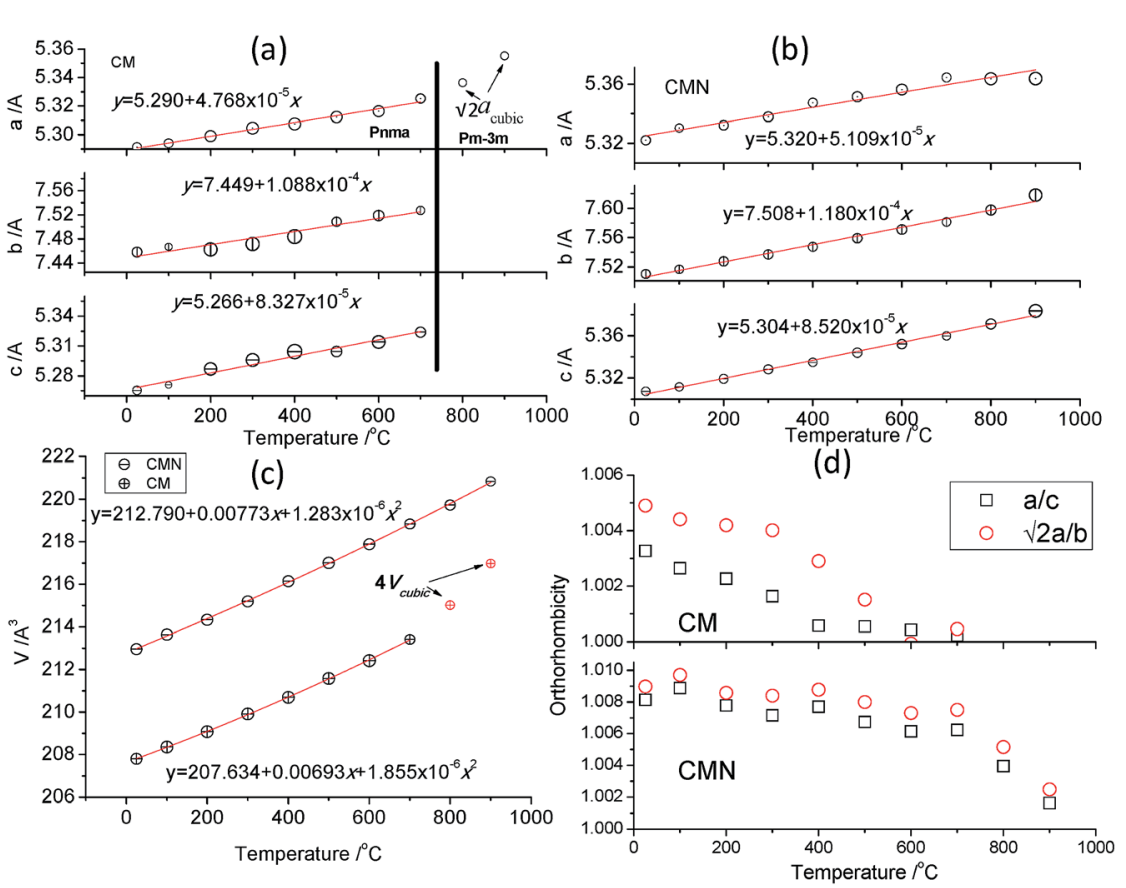

Fig. 5 Temperature dependence of lattice parameters for CM (a) and CMN (b) and their cell volume dependence on temperature (c). Error bars are within the symbols. (d) Shows the orthorhombicity of CM and CMN in terms of $a / c$ and $\sqrt{ } 2 a / c$. The linear fitting of the unit cell in selected temperature ranges is indicated in the respective graphs of (a) and (b) and the parabolic simulation of cell volume with temperature is indicated in (c). The unit cell parameter $\left(a_{\text {cubic }}\right)$ and volume $\left(V_{\text {cubic }}\right)$ of the cubic phase $(P m \overline{3} m)$ for $C M$ at 800 and $900{ }^{\circ} \mathrm{C}$ is scaled by $\sqrt{ } 2$ and 4 , respectively, for better comparison. 
diagram and the thermal expansion from $a-, b$ - and $c$-directions are listed in Table 2. The TECs calculated from $V^{1 / 3}(V=$ volume of unit cells) are in correspondence to those from dilatometry in the heating up stage. Previous studies ${ }^{17}$ on $\mathrm{CM}$ reported the existence of successive structural transitions from orthorhombic (Pnma) to tetragonal $(\mathrm{I} / \mathrm{mcm})$ at $896{ }^{\circ} \mathrm{C}$ and further to cubic $(\mathrm{Pm} \overline{3} \mathrm{~m})$ at $913{ }^{\circ} \mathrm{C}$, but we observed the change from orthorhombic to cubic structure at temperatures higher than $800{ }^{\circ} \mathrm{C}$ by analyzing the orthorhombicity of the structure, possibly due to the fast loss of oxygen due to the high surface area. It is obvious from the orthorhombicity that the addition of $\mathrm{Nb}$ clearly stabilizes the orthorhombic structure. A recent study has shown that chemical expansion is the result of two competing processes: ${ }^{32}$ the lattice contraction primarily due to electrostatic interaction and the lattice expansion due to the cation radius change. The exceptionally large unit cell parameter for $\mathrm{CM}$ at 800 and $900{ }^{\circ} \mathrm{C}$ could be the lattice expansion thanks to the higher concentration of $\mathrm{Mn}^{3+}$ cation in the lattice due to the loss of oxygen. The thermal expansion is anisotropic and the thermal expansion in $a$-direction is much smaller than those in the $b$ - and $c$-direction. Basically, the addition of $10 \% \mathrm{Nb}$ in $\mathrm{CM}$ increases slightly the thermal expansion in the $a$-, $b$ - and $c$-direction from the high temperature XRD, but wider temperature range for $\mathrm{CMN}$ could bring in more contribution from chemical expansion. The variation in temperature on $\mathrm{CM}$ between $25^{\circ} \mathrm{C}$ and $800{ }^{\circ} \mathrm{C}$ showed a volumetric increase of $2.45 \%,{ }^{33}$ slightly smaller than the value of this study (3.26\%). The high temperature XRD analysis of $\mathrm{CaMn}_{0.98} \mathrm{Nb}_{0.02} \mathrm{O}_{3}$ in the temperature between $25{ }^{\circ} \mathrm{C}$ and $900{ }^{\circ} \mathrm{C}$ showed a volumetric increase of $4.40 \%$ (ref. 27) and turned out to be a cubic structure at $900{ }^{\circ} \mathrm{C}$. The discrepancy in thermal expansion between different studies could be explained by a difference in the oxygen content in $\mathrm{CM}$ due to thermal history that can contribute to the chemical expansion at elevated temperatures. ${ }^{31}$

\section{Microstructure of the powders and oxygen electrode}

In order to improve the sinterability of the powder at $950{ }^{\circ} \mathrm{C}$ for better bonding between the oxygen electrode and electrolyte, the hand-ground powder was milled in a high-energy planetary milling machine for finer particles. The powder and milling media was mixed in isopropanol milled at a high speed of $650 \mathrm{rpm}$ for 30 min. Transmission electron microscopy (TEM) and scanning electron microscopy (SEM) were used to analyze the fine powder after high energy milling and the results are shown in Fig. 6 and 7, respectively. It can be seen that the particle size of both materials is in the range between $10 \mathrm{~nm}$ to $2 \mu \mathrm{m}$ and the CMN particles are slightly finer than those of CM. Amorphous phases are found in both CM and CMN. In particular, the former consists of small polycrystalline particles and

Table 2 Thermal expansion values of $C M$ and CMN from high temperature XRD in selected temperature ranges. The unit of thermal expansion is ppm K $\mathrm{K}^{-1}$

\begin{tabular}{lcccc}
\hline & $A$ & $b$ & $c$ & $V^{1 / 3}$ \\
\hline $\mathrm{CM} 25-700{ }^{\circ} \mathrm{C}$ & 9.0 & 14.6 & 15.8 & 13.6 \\
$\mathrm{CMN} 25-900^{\circ} \mathrm{C}$ & 9.5 & 15.7 & 16.1 & 13.8
\end{tabular}



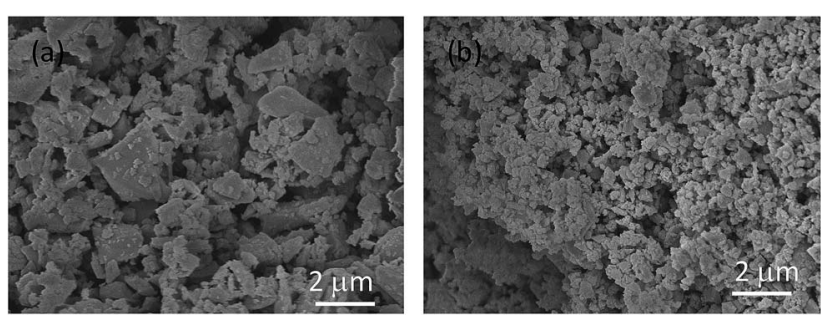

Fig. 6 SEM images of CM (a) and CMN (b) after milling with high-energy planetary milling.

covered with an amorphous layer while the latter composes of mostly a single crystal. The calculated $d$-spacings of the selected areas of CM and CMN are 0.257 $\mathrm{nm}$ and $0.271 \mathrm{~nm}$ respectively, as indicated in the Fig. 7, which could correspond to the (121) crystal planes.

The screen-printed layers (20-30 $\mu \mathrm{m}$ in thickness) composed of CM and CMN after calcination at $950{ }^{\circ} \mathrm{C}$ for two hours show good bonding to the YSZ electrolyte and similar grain size compared to the raw powder, as shown in Fig. 8. The grains lost their sharp edges in the sintering process and connected well to each other, which is beneficial to the transport of electrons.

\section{Electrochemical characterization}

Electrochemical impedance spectroscopy was used to evaluate a symmetricalelectrode system $(\mathrm{CM}(\mathrm{N})|\mathrm{YSZ}| \mathrm{CM}(\mathrm{N}))$ to study the polarization resistance of the electrode at OCV in static air, as shown in Fig. 9. The Nyquist and Bode plots of the symmetrical electrode at $700{ }^{\circ} \mathrm{C}$ are shown in Fig. 9(a). One arc can be distinguished for the $\mathrm{CMN}$ electrode, while two arcs for $\mathrm{CM}$ after analyzing the Bode plots. The Arrhenius plots of the series resistance and polarization resistance are shown in Fig. 9(b) and (c). $R_{\mathrm{s}}$ is obtained from the high-frequency intersection between the Nyquist plots and $x$-axis, and $R_{\mathrm{p}}$ is calculated by the reduction of $R_{\mathrm{S}}$ from the low frequency intersection between the Nyquist plots and $x$-axis. The $\log \left(R_{\mathrm{s}}\right)$ shows a linear plot against the reciprocal of temperature $(1000 / T)$ and activation energy of $0.8 \mathrm{eV}$, which is slightly lower than the activation energy $\left(>1.0 \mathrm{eV} \text { below } 650{ }^{\circ} \mathrm{C}\right)^{34}$ of YSZ in the temperature below $700{ }^{\circ} \mathrm{C}$. The $R_{\mathrm{s}}$ may compose of two parts: the ohmic resistance of YSZ electrolyte and CM or CMN
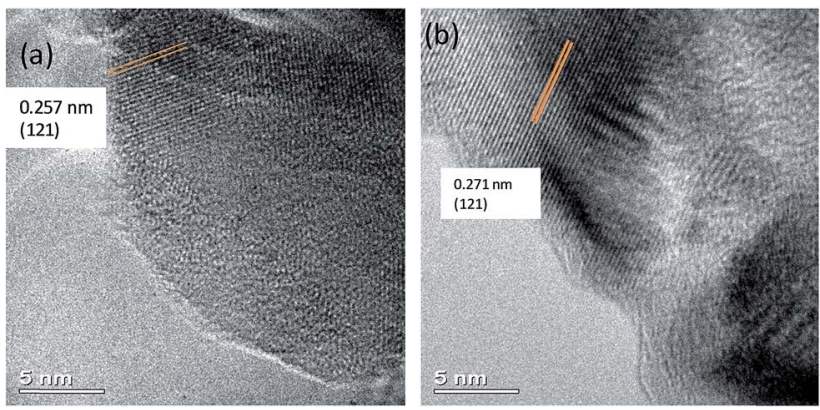

Fig. 7 Transmission electron microscopy images of CM (a) and CMN (b). 

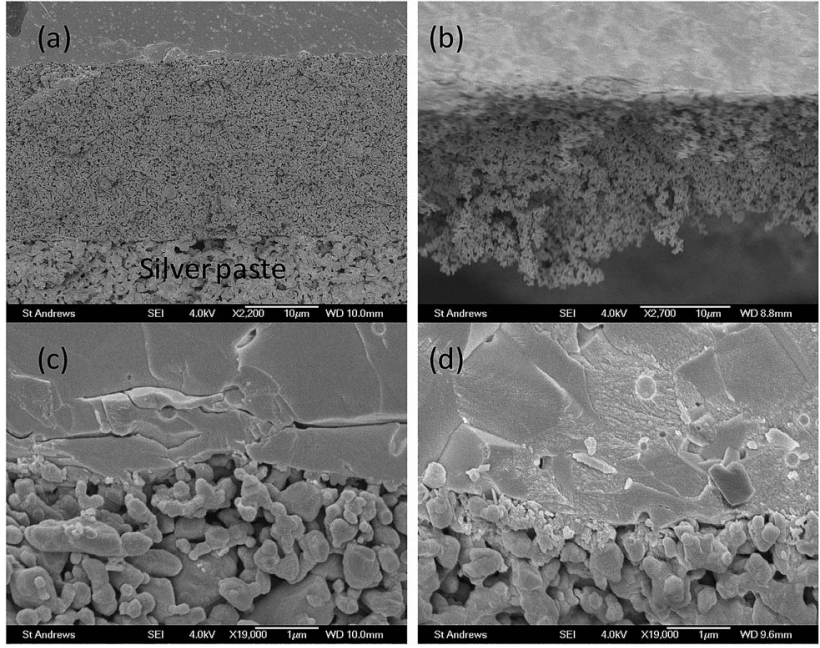

Fig. 8 SEM images of post-test CM ( $a$ and $c$ ) and CMN (b and d) after calcination at $950{ }^{\circ} \mathrm{C}$ for 2 hours in air and testing at $700{ }^{\circ} \mathrm{C}$ for symmetrical cells.

electrode. Even though the conductivity of $\operatorname{CMN}\left(125 \mathrm{~S} \mathrm{~cm}^{-1}\right.$ at $\left.700{ }^{\circ} \mathrm{C}\right)$ is higher than that of $\mathrm{CM}\left(1-5 \mathrm{~S} \mathrm{~cm}^{-1}\right.$ at $\left.700{ }^{\circ} \mathrm{C}\right),{ }^{12,19}$ the $R_{\mathrm{s}}$ for both electrodes are similar, indicating that the ohmic loss from the electrode is negligible. The $R_{\mathrm{p}}$ values for the CM and CMN electrodes are 3.40 and $5.53 \Omega \mathrm{cm}^{2}$, respectively and are quite close to that of LSM/YSZ oxygen electrode on YSZ electrolyte $\left(\sim 4 \Omega \mathrm{cm}^{2}\right)$ at 700 ${ }^{\circ} \mathrm{C} ., 35$ The polarization resistance of $\mathrm{CM}$ or $\mathrm{CMN}$ on YSZ at $700{ }^{\circ} \mathrm{C}$ is much smaller than that of $\mathrm{SrMnO}_{3}$ or $\mathrm{CM} / \mathrm{Gd}_{0.1} \mathrm{Ce}_{0.9} \mathrm{O}_{2-\delta}$ (CGO) composite on CGO electrolyte at $700{ }^{\circ} \mathrm{C}\left(\sim 8 \Omega \mathrm{cm}^{2}\right)^{11,14}$ and LSM electrode on YSZ $\left(\sim 10 \Omega \mathrm{cm}^{2}\right.$ at $\left.800{ }^{\circ} \mathrm{C}\right) .{ }^{6}$ PorrasVazquez et $a .^{11}$ found that the composite electrode $\mathrm{CaMn}_{0.95} \mathrm{Si}_{0.05} \mathrm{O}_{3-\delta} / \mathrm{CGO}$ showed a lower area-specific resistance (ASR) $\left(0.35 \Omega \mathrm{cm}^{2}\right.$ at $\left.800^{\circ} \mathrm{C}\right)$ than $\mathrm{CM} / \mathrm{GDC}$ $\left(1.5 \Omega \mathrm{cm}^{2}\right.$ at $\left.800{ }^{\circ} \mathrm{C}\right)$ and the increase of electric conductivity due to Si doping was thought to be the reason. With the benefit of higher ionic conductivity, the addition of CGO can decrease the electronic conductivity of the electrode. It was reported that the doping of $10 \% \mathrm{Ta}, 10 \% \mathrm{Nb}$ or $5 \%$ Mo on B site stabilized the lowtemperature cubic structure of $(\mathrm{La}) \mathrm{SrCo}(\mathrm{Fe}) \mathrm{O}_{3-\delta}$ to avoid the negative effect of intermediate hexagonal structure for better performance, ${ }^{28,29,36-38}$ while in our case the addition of $\mathrm{Nb}$ stabilized the low temperature-orthorhombic structure that showed inferior performance than the undoped CM. The addition of YSZ into LSM as oxygen electrode was reported to enhance the performance of electrode by a factor of two at $800{ }^{\circ} \mathrm{C}$ (ref. 39) due to the enlargement of triple phase boundary (TPB), since LSM showed an ionic conductivity as low as $10^{-7} \mathrm{~S} \mathrm{~cm}^{-1}$. 9 Two linear regions are implied in the Arrhenius plots and the activation energies in the temperature range $650-700{ }^{\circ} \mathrm{C}$ are twice as large as those in $540-620{ }^{\circ} \mathrm{C}$. The changes in activation energy are ascribed to the shifting of rate-limiting step from bulk diffusion limiting to surface diffusion limiting as the temperature increases since the activation energy of the bulk diffusivity is normally half of the surface diffusivity. ${ }^{40,41}$ 


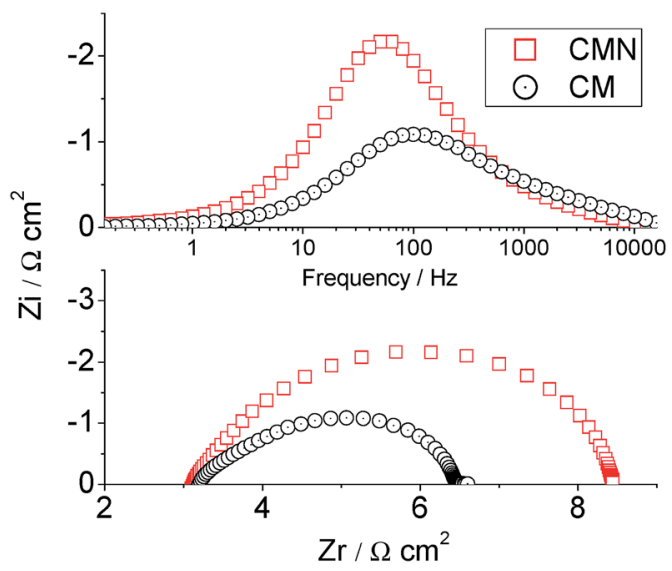

(a)

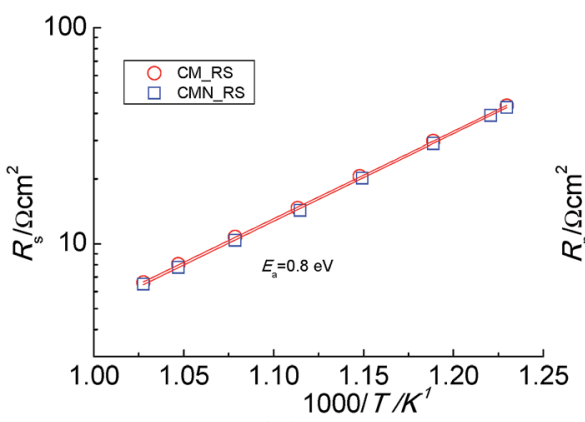

(b)

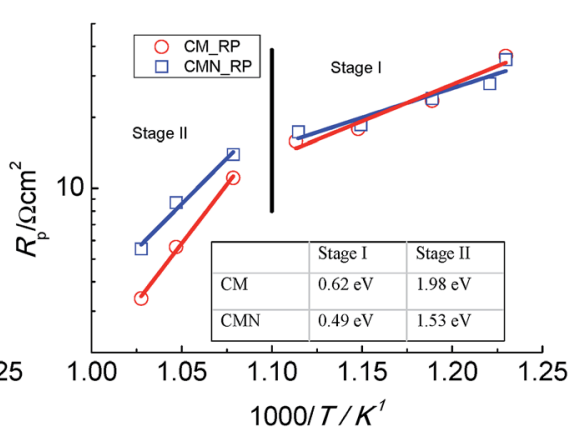

(c)

Fig. 9 (a) The impedance spectra (Nyquist plots and bode plots) of $\mathrm{CM}$ and $\mathrm{CMN}$ at $700^{\circ} \mathrm{C}$ in static air. Arrhenius plots of the $R_{\mathrm{s}}$ (b) and $R_{\mathrm{p}}$ (c) at OCV before activation for the symmetrical cells in the temperature range between 550 to $700{ }^{\circ} \mathrm{C}$. The activation energies of $R_{\mathrm{s}}$ and $R_{\mathrm{p}}$ are indicated in the respective diagrams.

In order to study the properties of the electrodes under current load, a threeelectrode system with a reference electrode was used for the electrolysis measurement. The fuel electrode was $\mathrm{Ni}(\mathrm{O})-\mathrm{YSZ}$ under $\mathrm{N}_{2}-50 \% \mathrm{H}_{2} \mathrm{O}-3 \% \mathrm{H}_{2}$ at a flow rate of $500 \mathrm{~mL} \mathrm{~min}{ }^{-1}$. Fig. 10 shows the typical impedance spectrum of the electrolysis cell with CMN as the oxygen electrode at OCV. The impedance spectrum between the reference and either anode or cathode allows one to determine the electrode loss from the nonohmic part of the spectrum. In a three-electrode system, the improper placement of the reference and working electrodes will give erroneous results. It is noteworthy that the ohmic resistances in both spectra are quite close, and almost one-half of the total ohmic resistance of the cell as indicated from the two-electrode testing, showing that the reference electrode is sampling the potential near the centre of the electrolyte. Furthermore, the characteristic frequencies, $\nu^{*}$, for the fuel electrode spectra, 200 and $2 \mathrm{kHz}$, are different from that for the oxygen electrode, 80 Hz. For this cell, the fuel electrode and oxygen electrode impedances are 0.5 and 1.5 $\Omega \mathrm{cm}^{2}$, respectively, showing the fuel electrode contributes a minor amount to the polarization resistance of the whole cell. The difference in $R_{\mathrm{p}}\left(1.5 v s .5 .53 \Omega \mathrm{cm}^{2}\right)$ 


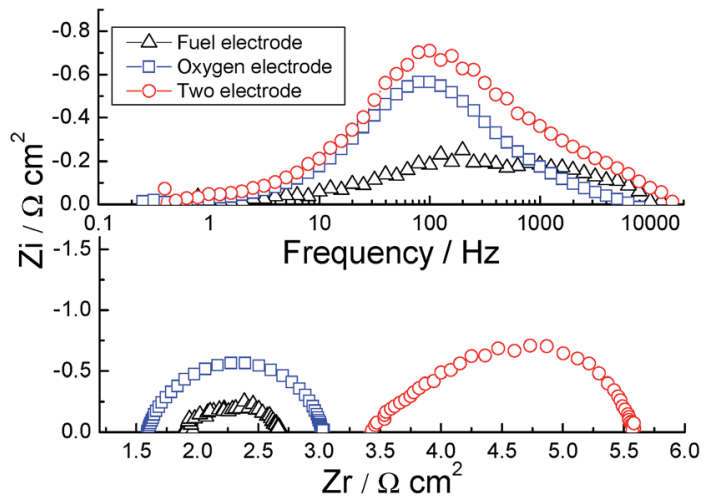

Fig. 10 Impedance with three-electrode system for the CMN oxygen electrode, Ni/YSZ hydrogen electrode and the whole electrolyser.

between the three electrode measurement and the previous symmetrical-cell measurement is caused by the additional activation of the oxygen electrode under $100 \mathrm{~mA} \mathrm{~cm}{ }^{-2}$ cathodic current for 24 hours in the former case. It should be noted that the characteristic frequency of the CMN electrode is the same, $80 \mathrm{~Hz}$, in both two electrode and three electrode systems. The electrodes can also be activated with anodic current since the same $R_{\mathrm{p}}$ of $1.5 \Omega \mathrm{cm}^{2}$ was observed if a $100 \mathrm{~mA} \mathrm{~cm}{ }^{-2}$ current was passed through the symmetrical cell where a cathodic current for one electrode is anodic for the other. Similar polarization hysteresis has been observed in the LSM/ YSZ electrode, ${ }^{5,42}$ in which polarization resistance decreased after both cathodic and anodic current passage.

The $I V$ curves of the electrolysis in the voltage range between $-1.7 \mathrm{~V}$ to $-0.82 \mathrm{~V}$ are shown in Fig. 11, where both $I V$ curves show good linearity. The open circuit voltages (OCV) of both electrodes are $0.82 \mathrm{~V}$, which is consistent with the

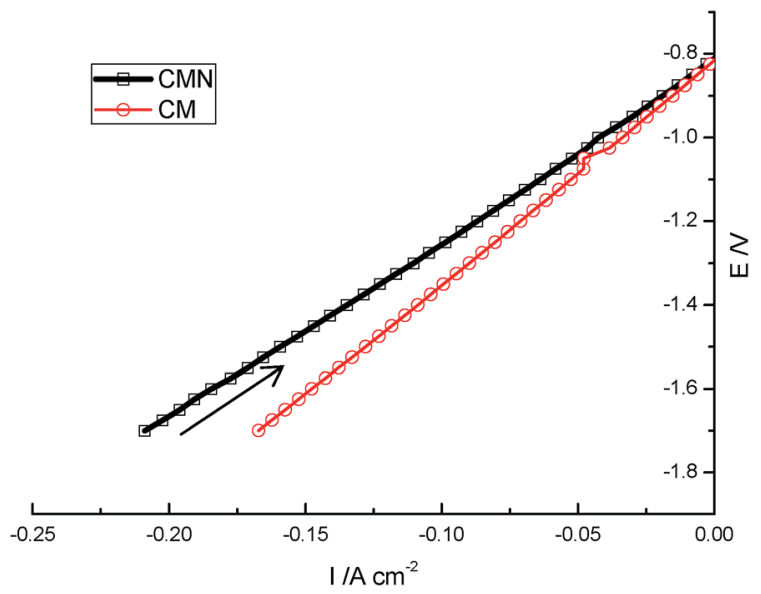

Fig. 11 IV curves of the electrolyser with $\mathrm{CM}$ and $\mathrm{CMN}$ oxygen electrode after activation for 24 hours under cathodic current $100 \mathrm{~mA} \mathrm{~cm}^{-2}$. The steam electrode is Ni/YSZ in $\mathrm{N}_{2}-50 \% \mathrm{H}_{2} \mathrm{O}-3 \% \mathrm{H}_{2}$ at a flow rate of $500 \mathrm{~mL} \mathrm{~min}^{-1}$. 
theoretical Nernst voltage calculated between air and $\mathrm{N}_{2}$ flow containing $50 \%$ $\mathrm{H}_{2} \mathrm{O}-3 \% \mathrm{H}_{2}$ at $700{ }^{\circ} \mathrm{C}$. The maximum current at $-1.7 \mathrm{~V}$ is $0.21 \mathrm{~A} \mathrm{~cm}^{2}$ and $0.17 \mathrm{~A}$ $\mathrm{cm}^{2}$ for the CMN and CM electrodes, respectively. The ASR calculated from the $I V$ curve is 5.3 and $4.2 \Omega \mathrm{cm}^{2}$ for the electrolyser with a CM and CMN oxygen electrode, respectively. The ASR value for the electrolyser with a CMN oxygen electrode are $20 \%$ smaller than that calculated from the impedance spectrum at OCV, $5.5 \Omega$ $\mathrm{cm}^{2}$. Since the anode is kept as the same for both electrolysers, the difference in performance is attributed to the catalytic activity of the oxygen electrode for the oxidation of $\mathrm{O}^{2-}$ to $\mathrm{O}_{2}$. According to the impedance measurement, the ohmic loss from the $1 \mathrm{~mm}$ thick YSZ electrolyte contributes a large portion of the total loss at $700{ }^{\circ} \mathrm{C}$. However, this configuration does not affect the comparison between the two materials as oxygen electrodes for oxygen oxidation.

The Nyquist and Bode plots of the CM electrode are shown in Fig. 12(a). The characteristic frequencies for CM increase to a higher frequency after activation under $100 \mathrm{~mA} \mathrm{~cm}^{-2}$ cathodic current, which could be attributed to the change of surface and capacitance. The polarization resistance of the oxygen electrode under bias was measured using impedance and presented in Fig. 12(b). However, CM presents a polarization resistance of $0.059 \Omega \mathrm{cm}^{2}$ under $-0.4 \mathrm{~V}$ bias as the cathode for fuel cell operation while CMN gives a polarization resistance of 0.081 $\Omega \mathrm{cm}^{2}$ under $0.4 \mathrm{~V}$ bias as the anode for the electrolysis process. Considering the $R_{\mathrm{S}}$ is higher than $R_{\mathrm{p}}$ for both electrodes at all biases, the maximum actual voltage loss on the electrode under a bias of $0.4 \mathrm{~V}$ is lower than $0.2 \mathrm{~V}$, which is quite a reasonable loss for the oxygen electrode in either fuel cell or electrolyser modes. The reversible decrease in impedance upon cathodic polarization of LSM-based electrodes has been observed by several groups, and the mechanism was not definitely clear, ${ }^{\mathbf{4 3 4}}$ but the reduction of LSM surface could be involved in the activation process. Similarly, the loss of oxygen on the surface of CM during the reduction process could result in the formation of vacancies through eqn (2), ${ }^{45}$ which are beneficial to fast transport of the oxygen ion in the electrode.

$$
\frac{1}{2} \mathrm{O}_{2}(\mathrm{~g})+V_{\mathrm{O}}^{*}+2 \mathrm{Mn}_{\mathrm{Mn}}^{\prime}=\mathrm{O}_{\mathrm{O}}^{\times}+2 \mathrm{Mn}_{\mathrm{Mn}}^{\times}
$$
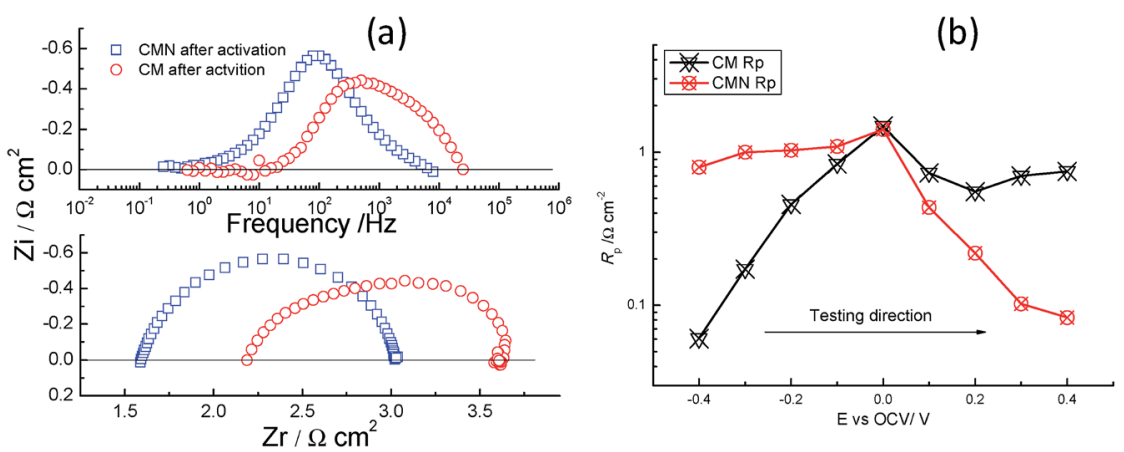

Fig. 12 Nyquist and Bode plots (a) of the CM and CMN cathodes at $700{ }^{\circ} \mathrm{C}$ in static air at OCV immediately after the activation at $100 \mathrm{~mA} \mathrm{~cm}^{-2}$ cathodic current for 24 hours. (b) is the $R_{\mathrm{p}}$ measured under bias for both electrodes with three-electrode system. The counter electrode is a Ni/YSZ electrode in $\mathrm{N}_{2}-50 \% \mathrm{H}_{2} \mathrm{O}-3 \% \mathrm{H}_{2}$ at a flow rate of $500 \mathrm{~mL} \mathrm{~min}^{-1}$. 
Here, the Kroger-Vink notations are used. ${ }^{46}$ The oxygen vacancies could also be ordered to be immobile and the highest conductivity for CM was achieved at $\delta=$ 0.08 where no oxygen vacancy was observed. ${ }^{47,48}$ Under anodic current, the decrease in the non-stoichiometry due to the absorption of $\mathrm{O}_{2}$ means the loss of oxygen vacancies, and explains the resultant decrease of performance in the bias range of 0.2-0.4 V. Aguadero et al. ${ }^{29}$ stipulated that the performance increase of $\mathrm{SrCo}_{1-x} \mathrm{Mo}_{x} \mathrm{O}_{3}$ oxygen electrode under anodic current was due to the increase of p-type carriers that improves the electrocatalytic properties. This may help to explain the decrease of performance of CM a typical n-type oxide ${ }^{48}$ under anodic current. On the other hand, because $\mathrm{CMN}$ is more difficult to be reduced as demonstrated in the TGA curves, there is only a slight improvement in the performance under cathodic current due to the negligible increase of oxygen vacancies. CMN can be more stable under anodic current that preserves the oxygen vacancy for the transport of oxygen ions. Moreover, an oxygen-excess CMN $\left(\delta=-0.1\right.$ ) was synthesized with high oxygen pressure, ${ }^{15}$ and it was not very clear if the interstitial oxygen could also be a route of oxygen transport. ${ }^{47,49}$

\section{Conclusion}

CM and CMN were examined as oxygen electrodes for SOEs and SOFCs. The addition of $10 \mathrm{~mol} \% \mathrm{Nb}$ on the $\mathrm{B}$ site of perovskite improved the thermal stability of $\mathrm{CM}$ in air and oxygen up to $900{ }^{\circ} \mathrm{C}$. Both materials showed a thermal expansion of 10.8-10.9 $\mathrm{ppm} \mathrm{K}^{-1}$, close to that of YSZ $\left(\sim 11 \mathrm{ppm} \mathrm{K}^{-1}\right)$. At $700{ }^{\circ} \mathrm{C}, \mathrm{CM}$ as a cathode for SOFCs could achieve a polarization resistance less than $0.1 \Omega \mathrm{cm}^{2}$, but CMN showed superior performance $\left(R_{\mathrm{p}}<0.1 \Omega \mathrm{cm}^{2}\right.$ at $0.4 \mathrm{~V}$ bias $)$ as an anode for SOECs. The performance of the electrode can be further improved by mixing with ionic conductors to make a composite electrode. A possible exploration of the materials with a $\mathrm{Nb}$ content less than $10 \mathrm{~mol} \%$ doping on $\mathrm{Mn}$ site would lead to a better oxygen electrode performance in both SOFC and SOE mode.

\section{Acknowledgements}

We thank EPSRC for funding under the contract of H2FC hub EPSRC: EP/J016454/ 1 and Platform EPSRC: EP/K006800/1 and JTSI thanks Wolfson Merit of Royal Society of Chemistry: WRMA 2012/R2.

\section{References}

1 Q. Cai, C. S. Adjiman and N. P. Brandon, J. Power Sources, 2014, 268, 212-224.

2 G. Tsekouras and J. T. S. Irvine, J. Mater. Chem., 2011, 21, 9367-9376.

3 S. H. Jensen, P. H. Larsen and M. Mogensen, Int. J. Hydrogen Energy, 2007, 32, 3253-3257.

4 Y. Shin, W. Park, J. Chang and J. Park, Int. J. Hydrogen Energy, 2007, 32, 14861491.

5 W. Wang, Y. Huang, S. Jung, J. M. Vohs and R. J. Gorte, J. Electrochem. Soc., 2006, 153, A2066-A2070.

6 Y. Bo, Z. Wenqiang, X. Jingming and C. Jing, Int. J. Hydrogen Energy, 2008, 33, 6873-6877. 
7 W. Wang, M. D. Gross, J. M. Vohs and R. J. Gorte, J. Electrochem. Soc., 2007, 154, B439-B445.

8 H. Uchida, N. Osada and M. Watanabe, Electrochem. Solid-State Lett., 2004, 7, A500-A502.

9 J. M. Vohs and R. J. Gorte, Adv. Mater., 2009, 21, 943-956.

10 K. Kuroda, N. Ishizawa, N. Mizutani and M. Kato, J. Solid State Chem., 1981, 38, 297-299.

11 J. M. Porras-Vazquez, E. R. Losilla, P. J. Keenan, C. A. Hancock, T. F. Kemp, J. V. Hanna and P. R. Slater, Dalton Trans., 2013, 42, 5421-5429.

12 G. Xu, R. Funahashi, Q. Pu, B. Liu, R. Tao, G. Wang and Z. Ding, Solid State Ionics, 2004, 171, 147-151.

13 C. A. Hancock and P. R. Slater, Dalton Trans., 2011, 40, 5599-5603.

14 J. M. Porras-Vazquez, T. F. Kemp, J. V. Hanna and P. R. Slater, J. Mater. Chem., 2012, 22, 8287-8293.

15 A. Kruth, U. Guth and A. R. West, J. Mater. Chem., 1999, 9, 1579-1583.

16 C. A. Hancock, A. L. Ong, P. R. Slater and J. R. Varcoe, J. Mater. Chem. A, 2014, 2, 3047-3056.

17 H. Taguchi, M. Nagao, T. Sato and M. Shimada, J. Solid State Chem., 1989, 78, 312-315.

18 T. E. F. Lichtenthaler, Master, Universitetsbiblioteket i Oslo, 2006.

19 M. E. Melo Jorge, A. Correia dos Santos and M. R. Nunes, Int. J. Inorg. Mater., 2001, 3, 915-921.

20 H. Yokokawa, N. Sakai, T. Kawada and M. Dokiya, Solid State Ionics, 1990, 4041(Part 1), 398-401.

21 P. V. Riboud and A. Muan, J. Am. Ceram. Soc., 1963, 46, 33-36.

22 E. Y. Konysheva, X. Xu and J. T. S. Irvine, Adv. Mater., 2012, 24, 528-532.

23 E. Konysheva and J. T. S. Irvine, J. Mater. Chem., 2008, 18, 5147-5154.

24 R. S. Roth, J. Res. Natl. Bur. Stand., 1957, 58, 75-88.

25 B. Dabrowski, O. Chmaissem, J. Mais, S. Kolesnik, J. D. Jorgensen and S. Short, J. Solid State Chem., 2003, 170, 154-164.

26 H. Yokokawa, N. Sakai, T. Kawada and M. Dokiya, Solid State Ionics, 1992, 52, 43-56.

27 L. Bocher, M. H. Aguirre, R. Robert, D. Logvinovich, S. Bakardjieva, J. Hejtmanek and A. Weidenkaff, Acta Mater., 2009, 57, 5667-5680.

28 W. Zhou, Z. Shao, R. Ran, W. Jin and N. Xu, Chem. Commun., 2008, 5791-5793.

29 A. Aguadero, D. Pérez-Coll, J. A. Alonso, S. J. Skinner and J. Kilner, Chem. Mater., 2012, 24, 2655-2663.

30 V. Oygarden and T. Grande, Dalton Trans., 2013, 42, 2704-2715.

31 X. Chen, J. Yu and S. B. Adler, Chem. Mater., 2005, 17, 4537-4546.

32 D. Marrocchelli, S. R. Bishop, H. L. Tuller and B. Yildiz, Adv. Funct. Mater., 2012, 22, 1958-1965.

33 Q. Zhou and B. J. Kennedy, J. Phys. Chem. Solids, 2006, 67, 1595-1598.

34 J. T. S. Irvine, I. R. Gibson and D. P. Fagg, Ionics, 1995, 1, 279-285.

35 J. Kim, H.-I. Ji, H. P. Dasari, D. Shin, H. Song, J.-H. Lee, B.-K. Kim, H.-J. Je, H.-W. Lee and K. J. Yoon, Int. J. Hydrogen Energy, 2013, 38, 1225-1235.

36 V. Cascos, R. Martínez-Coronado and J. A. Alonso, Int. J. Hydrogen Energy, 2014, 39, 14349-14354.

37 B. Qu, W. Long, F. Jin, S. Wang and T. He, Int. J. Hydrogen Energy, 2014, 39, 12074-12082. 
38 S. Yoo, J. Kim, S. Y. Song, D. W. Lee, J. Shin, K. M. Ok and G. Kim, RSC Adv., 2014, 4, 18710-18717.

39 S. Wang, Y. Jiang, Y. Zhang, J. Yan and W. Li, J. Electrochem. Soc., 1998, 145, 1932-1939.

40 H. K. B. W. David Kingery and D. R. Uhlmann, Introduction to Ceramics, John Wiley \& Sons, Inc, 2nd edn, 1976.

41 Z. Shao and S. M. Haile, Nature, 2004, 431, 170-173.

42 M. Liang, B. Yu, M. Wen, J. Chen, J. Xu and Y. Zhai, J. Power Sources, 2009, 190, 341-345.

43 S. P. Jiang and J. G. Love, Solid State Ionics, 2001, 138, 183-190.

44 M. J. Jørgensen, S. Primdahl and M. Mogensen, Electrochim. Acta, 1999, 44, 4195-4201.

45 E. Goldyreva, I. Leonidov, M. Patrakeev and V. Kozhevnikov, J. Solid State Electrochem., 2012, 16, 1187-1191.

46 F. A. Kröger and H. J. Vink, in Solid State Physics, ed. S. Frederick and T. David, Academic Press, 1956, vol. 3, pp. 307-435.

47 A. Reller, J. M. Thomas, D. A. Jefferson and M. K. Uppal, Proc. R. Soc. London, Ser. A, 1984, 394, 223-241.

48 M. Schrade, R. Kabir, S. Li, T. Norby and T. G. Finstad, J. Appl. Phys., 2014, 115, 103705.

49 J. B. Goodenough, Annu. Rev. Mater. Res., 2003, 33, 91-128. 